\title{
Antibodies against Nitric Oxide Damaged Poly L-Tyrosine and 3-Nitrotyrosine Levels in Systemic Lupus Erythematosus
}

\author{
Fozia Khan and Rashid Ali* \\ Department of Biochemistry, Faculty of Medicine, A.M.U. Aligarh-202002, U.P., India
}

Received 7 Oct 2005, Accepted 9 Jan 2006

\begin{abstract}
Alterations in the amino acid structure or sequence can generate neo-epitopes from self-proteins causing autoaggressive immune attack. Reactive nitrogen species are an important factor that induces post-translational modification of proteins by cellular reduction and oxidation mechanism; cysteinyl-nitrosylation or tyrosine nitration leading to potentially pathogenic pathways. It was thought of interest to investigate the immunogenicity of nitrated poly L-tyrosine vis-à-vis its possible role in the induction of antibodies in systemic lupus erythematosus (SLE). Commercially available poly L-tyrosine was exposed to nitrating species and the damage was monitored by UV spectroscopy and alkaline gel electrophoresis. The results indicated the formation of 3-nitrotyrosine. Nitrated poly Ltyrosine induced higher titre antibodies as compared to the native form. Nitrated poly L-tyrosine was recognized by the autoantibodies present in the sera of patients suffering from SLE by enzyme immunoassays and band shift assay. The possible role of nitrated self-proteins has been discussed in the production of circulating anti-DNA antibodies in SLE.
\end{abstract}

Keywords: Nitric oxide, 3-Nitrotyrosine, Poly L-tyrosine, SLE autoantibodies

\section{Introduction}

Nitric oxide (NO) is a diffusible messenger known to display a variety of physiological functions, including vasorelaxation, bronchodilation, inhibition of platelet aggregation, and neurotransmission. Additionally, it appears to be involved in the macrophage-dependent killing of intracellular parasites and possibly cancer cells, indicating the potential of this free

*To whom correspondence should be addressed.

Tel: 91-571-3295535; Fax: 91-571-2506163

E-mail: raliamu@yahoo.com radical to mediate cytotoxic and pathological effects. When produced in excess, NO can have a multitude of potentially toxic effects, which are highly dependent on its concentration and the particular microenvironment in which it is produced (Brito et al., 1999). NO has been reported to inhibit mitochondrial respiration (Cassina and Radi, 1996; Brown et al., 1997) and ribonucleotide reductase (Lepoivre et al., 1991) and to damage DNA (Nguyen et al., 1992) and bring about protein modification (Oates et al., 1999). Nitric oxide damage in DNA exposes base residues in the backbone and the minor regions of single-stranded DNA (ssDNA), rendering it highly immunogenic (Dixit and Ali, 2004). The free radical damage to proteins results mainly in the modification of amino acid residues, side chain crosslinking and fragmentation. The aromatic amino acids and cysteine are more susceptible to modification affecting the general properties of the protein such as change in charge, hydrophobicity and conformation (Davies, 1987; Davies et al., 1987; Davies and Delsignor, 1987). L-tyrosine and protein bound L-tyrosine are attacked by various reactive nitrogen intermediates (RNI) including peroxynitrite to form 3-nitrotyrosine (3-NT) and protein associated 3-nitrotyrosine (Tsikas and Caidahl, 2005). Tyrosine nitration is a post-translational modification in proteins that occurs under conditions of oxidative stress and plays a role in the pathogenesis of diseases such as asthma (Xiao et al., 2005), Alzheimer's disease (Reynolds et al., 2005), atherosclerosis, endotoxic shock, human acute lung injury (Brito et al., 1999), systemic lupus erythematosus (Oates et al., 1999) and rheumatoid arthritis (Kaur and Halliwell, 1994).

There is increasing evidence that NO may be involved in the pathogenesis of SLE (Wanchu et al., 1998; Lopez-Nevot et al., 2003) which is a multisystem autoimmune disease involving both humoral and cellular aspects of the innate and acquired immune system (Robert and Kimberly, 2001). The disease is characterized by the circulating autoantibodies against a variety of cell antigens (Scofield et al., 2005). Murine models of SLE demonstrate abnormally high levels of NO compared with normal mice, while systemic blockade of NO production reduces disease severity. Two potential 
sources of excessive NO are activated endothelial cells and keratinocytes via up regulated nitric oxide synthase (Belmont et al., 1997). Serum nitrite/nitrate level, which is an index of nitric oxide production, was found to correlate with SLE disease activity and with the levels of antibodies to dsDNA. Subjects with active lupus nephritis had higher levels of serum nitrotyrosine than those without renal disease, suggesting that overproduction of NO may play a pathogenic role in SLE and lupus nephritis (Gilkeson et al., 1999; Oates et al., 1999).

In the present study, commercially available poly L-tyrosine (PLT) was nitrated with nitric oxide generated by sodium nitrite. Antibodies were induced in rabbits against the nitrated form and were characterized with respect to antigen binding specificities. The crossreactivity of naturally occurring autoantibodies in SLE with nitrated-PLT (NO-PLT) has also been examined. The binding characteristics of SLE autoantibodies with native DNA, native and nitrated poly Ltyrosine and other nitrated nuclear antigens have been investigated and the role of nitrated self-proteins has been discussed in the etiopathogenesis of SLE.

\section{Material and Methods}

Chemical and reagents. Poly L-tyrosine, 3-nitrotyrosine, carboxyPTIO, uric acid, ascorbic acid, desferrioximine, BSA, calf thymus DNA, anti-human/anti-rabbit IgG-alkaline phosphatase conjugates were purchased from Sigma Chem. Co.. Polystyrene microtitre flat bottom ELISA plates having 96 wells $(7 \mathrm{~mm}$ diameter) were purchased from NUNC. Protein A-Sepharose CL-4B was from Genei, India. All other chemicals were of the highest analytical grade.

Nitration of poly L-tyrosine. Poly L-tyrosine was nitrated according to Ohshima et al. (1990). The $\mathrm{pH}$ of $5 \mathrm{mg} / \mathrm{ml}$ poly Ltyrosine solution was adjusted to 3.5 with acetic acid. Sodium nitrite $(200 \mathrm{mM})$ was added to the final concentration of $1 \mathrm{mM}$ and the solution was incubated at $37^{\circ} \mathrm{C}$ for $24 \mathrm{~h}$. Subsequently the solution was dialyzed overnight to PBS (10 $\mathrm{mM}$ sodium phosphate, $150 \mathrm{mM} \mathrm{NaCl}, \mathrm{pH} 9.0$ ).

Spectroscopic analysis. The ultraviolet spectra of the native and nitrated protein samples were recorded in the wavelength range of 230-500 nm on a Shimadzu UV-240 spectrophotometer. 3-Nitrotyrosine is a stable product and can be determined spectrophotometrically. Its absorbance maximum ranges from 350 to $450 \mathrm{~nm}$, shifting from $365 \mathrm{~nm}$ at acidic $\mathrm{pH}$ ( $\mathrm{pH}<3$, colourless) to $420 \mathrm{~nm}$ at basic $\mathrm{pH}$ ( $\mathrm{pH}>9$, yellow). The absorbance spectrum of a series of known concentrations of 3-nitrotyrosine at basic $\mathrm{pH}$ was used as reference to determine the concentration of 3-nitrotyrosine in nitrated protein samples. The modifications incurred on poly L-tyrosine were also analysed by UV difference spectroscopy.

Quantitation of protein nitration. The extent of nitration of poly L-tyrosine was quantitated by two methods. A calibration curve was drawn using different concentrations of 3-nitrotyrosine (Sigma). The absorbance of both 3-nitrotyrosine and nitrated poly L-tyrosine was measured at $420 \mathrm{~nm}$. The extent of nitration in poly
L-tyrosine was calculated from the calibration curve.

Nitration of poly L-tyrosine was also quantitated by competition ELISA (Khan et al., 1998). Standard nitrated BSA procured from Sigma. was coated onto the ELISA plate $(100 \mu \mathrm{l}$ from $1 \mathrm{mg} / \mathrm{ml})$ in triplicate and incubated at $37^{\circ} \mathrm{C}$ for $2 \mathrm{~h}$ and overnight at $4^{\circ} \mathrm{C}$. The plate was then washed twice with PBS-T $(+1 \%$ Tween 20$)$ and blocked with $2.5 \%$ ovalbumin to prevent non-specific binding. Immune complex was formed by incubating standard nitrated BSA dissolved in PBS $(0.02-0.5 \mathrm{mg} / \mathrm{ml})$ and nitrated poly L-tyrosine (upto $1: 10$ dilution) with constant concentration of polyclonal antinitrotyrosine rabbit IgG $(1: 30,000)$ purchased from Sigma, USA, at $37^{\circ} \mathrm{C}$ for $2 \mathrm{~h}$ and overnight at $4^{\circ} \mathrm{C}$. Immune complex $(100 \mu \mathrm{l})$ was coated to the ELISA plate. After incubation at $37^{\circ} \mathrm{C}$ for $2 \mathrm{~h}$ and overnight at $4^{\circ} \mathrm{C}$, the plate was washed 3 times with PBS-T. The plate was then coated with goat anti-rabbit IgG alkaline phosphatae conjugate $(1: 5000)$ for $2 \mathrm{~h}$ at $37^{\circ} \mathrm{C}$. The plate was washed extensively with PBS-T and the colour development was initiated by the addition of $100 \mu \mathrm{l}$ of $2.2 \mathrm{mM}$ p-nitrophenyl phosphate substrate in carbonate-bicarbonate buffer, $\mathrm{pH}$ 9.6. The plate was allowed to develop for up to $30 \mathrm{~min}$ at room temperature and terminated by the addition of $100 \mu \mathrm{l}$ of $4 \mathrm{M}$ sulphuric acid. The absorbance was read at $410 \mathrm{~nm}$ and a standard curve was drawn between absorbance and standard nitrated BSA concentration. The concentration of nitrated poly L-tyrosine was estimated from the standard curve.

Effect of quenchers on modification by nitric oxide. The effect of nitric oxide trapping agent (carboxy-PTIO at $10 \mathrm{mM}$ ), antioxidants (ascorbic acid at $10 \mathrm{mM}$, uric acid at $0.2 \mathrm{mM}$ ) on poly L-tyrosine nitration were studied by incubating the quencher with the nitrating reaction mixture and measuring hypochromicity at $280 \mathrm{~nm}$ (Yoshie and Ohshima, 1997).

Alkaline agarose gel electrophoresis. Alkaline agarose gel was cast in buffer containing $33 \mathrm{mM} \mathrm{NaOH}$ and $2 \mathrm{mM}$ EDTA. The $\mathrm{NaOH}$ and EDTA were added after agarose dissolution. The samples were prepared for loading by adding sample dye $(10 \%$ glycerol and $0.002 \%$ bromophenol blue). Electrophoresis was carried out at $30 \mathrm{~V}$ for $4 \mathrm{~h}$ in alkaline electrophoresis buffer (50 $\mathrm{mM} \mathrm{NaOH}, 1 \mathrm{mM}$ EDTA).

Serum samples. SLE sera were collected from Indian patients in the year 2004, from outdoor and indoor patients of Department of Medicine, All India Institute of Medical Sciences, New Delhi. The SLE sera satisfied the American College of Rheumatology criteria for its diagnosis (Arnett et al., 1988) showing high titre anti-DNA antibodies $(>1: 12,800)$. No patient had an active infection, known malignancy, tuberculosis, pregnancy, or cirrhosis. Normal human sera were obtained from healthy individuals and pooled. All serum samples were decomplemented by heating at $56^{\circ} \mathrm{C}$ for $30 \mathrm{~min}$ and stored at $-20^{\circ} \mathrm{C}$

Immunization schedule. Native and NO treated poly L-tyrosine solution $(50 \mathrm{mg} / \mathrm{ml})$ were emulsified with complete Freunds' adjuvant and injected intramuscularly in female rabbits. Subsequent injections were given in incomplete Freunds' adjuvant. Each animal received a total of $450 \mathrm{mg}$ of antigen in the course of 9 injections. Blood was collected from marginal vein of the ear. Serum was separated and decomplemented by heating at $56^{\circ} \mathrm{C}$ for 
30 min. Pre-immune serum was collected prior to immunization. The sera were stored in small aliquots at $-20^{\circ} \mathrm{C}$.

HPLC analysis. Separation of 3-nitrotyrosine was achieved by HPLC (Biologic Duo Flow System, BioRad, USA) and its concentration was calculated in the sera of immunized animals. Serum samples were diluted $1: 1(\mathrm{v} / \mathrm{v})$ with eluant buffer and filtered through $0.42 \mu \mathrm{m}$ Milex, disposable syringe filter before loading onto a C-18 reversed phase column $(25 \mathrm{~cm} \times 4.6 \mathrm{~mm})$ from Vydac, USA. The eluant buffer was $500 \mathrm{mM}$ potassium phosphate (pH 3.0) with $10 \%$ methanol (v/v). Samples were eluted at a flow rate of $0.8 \mathrm{ml} / \mathrm{min}$. 3-Nitrotyrosine (absorbance maxima- $274 \mathrm{~nm}$, at $\mathrm{pH}$ 3.0) in various samples was detected at four different wavelengths $(274,214,280$ and $410 \mathrm{~nm})$ by UV-visible multiple wavelength detector. Identification of the peak was carried out on the basis of the retention time of standard 3-nitrotyrosine and spiking experiments. The absorbance of two series of known concentrations of standard 3-nitrotyrosine at acidic $\mathrm{pH}(\mathrm{pH}<3.5)$ was used as reference to determine the concentration of 3-nitrotyrosine in the serum samples (Kaur and Halliwell, 1994).

Purification of immunoglobulin G. Immunoglobulin $G$ was isolated from preimmune, immune, pooled normal human sera, and from sera of various SLE patients, on a Protein-A Sepharose CL 4B affinity column. The homogeneity of isolated IgG was checked by performing $7.5 \%$ polyacrylamide gel electrophoresis (Dixit et al., 2003).

Modification of various polymers for crossreactivity studies. BSA, calf thymus DNA and chromatin (Mansoor et al., 2005) were nitrated according to Ohshima et al. (1990) as mentioned above. Poly L-tyrosine was also exposed to peroxynitrite by its incubation in $100 \mathrm{mM}$ sodium phosphate buffer, $\mathrm{pH} 7.4$, containing $1 \mathrm{mM}$ diethylenetriaminepentaacetic acid (DTPA), $1.0 \mathrm{mM}$ nitric oxide releasing compound [diethylamine NONOate (DEA-NO) and 1.0 $\mathrm{mM}$ 1,4-hydroquinone at $37^{\circ} \mathrm{C}$ for $1 \mathrm{~h}$ (Yoshie and Ohshima, 1997).

Enzyme linked immunosorbent assay. Antibodies were detected by ELISA using polystyrene microtitre plates as solid support (Ali and Alam, 2002). One hundred microlitre of $2.5 \mathrm{mg} / \mathrm{ml}$ antigen in protein coating buffer $\left(15 \mathrm{mM} \mathrm{Na}_{2} \mathrm{CO}_{3}, 35 \mathrm{mM} \mathrm{NaHCO}_{3}, \mathrm{pH} 9.6\right)$ was coated in test wells of microtitre plates, incubated for $2 \mathrm{~h}$ at $37^{\circ} \mathrm{C}$ and subsequently overnight at $4^{\circ} \mathrm{C}$. The antigen-coated wells were washed three times with TBS-T to remove unbound antigen. Unoccupied sites were blocked with $150 \mathrm{ml}$ of $1.5 \%$ fat free milk in TBS for $4-5 \mathrm{~h}$ at room temperature. The plates were washed once with TBS-T and antibody (100 ml/well) to be tested was diluted in TBS and added to each well. After $2 \mathrm{~h}$ incubation at $37^{\circ} \mathrm{C}$ and overnight at $4^{\circ} \mathrm{C}$, the plates were washed four times with TBS-T and an appropriate dilution of anti-immunoglobulin alkaline phosphatase conjugate was added to each well. After incubation at $37^{\circ} \mathrm{C}$ for $2 \mathrm{~h}$, the plates were washed four times with TBS-T and developed using p-nitrophenyl phosphate as substrate. The absorbance was recorded at $410 \mathrm{~nm}$ on an automatic microplate reader. Each sample was run in duplicate. The control wells were treated similarly but were devoid of antigen. Results were expressed as a mean of $\mathrm{A}_{\text {test }}-\mathrm{A}_{\text {control. }}$.
Competition ELISA. The antigenic specificity of the antibodies was determined by competition ELISA (Hasan et al., 1991). Varying amount of inhibitors $(0-20 \mathrm{mg} / \mathrm{ml})$ were mixed with a constant amount of antiserum. The mixture was incubated at room temperature for $2 \mathrm{~h}$ and subsequently overnight at $4^{\circ} \mathrm{C}$. The immune complex thus formed was coated in the wells instead of antibody. The remaining steps were the same as in direct binding ELISA. Percent inhibition was calculated using the formula:

Percent inhibition $=1-\frac{\mathrm{A}_{\text {inhibited }}}{\mathrm{A}_{\text {uninhibited }}} \times 100$

Statistical analysis. The data in Table 3 was analysed by one way analysis of variance (ANOVA) following the Student Newman Keuls method (all pairwise multiple comparison procedures); a value of $p<0.01$ was considered statistically significant.

Gel retardation assay. Gel retardation assay was performed to visualize antigen-antibody interaction in gel (Waris and Alam, 2004). Constant amount of IgG (20 mg) was incubated with varying concentration of nitrated poly L-tyrosine $(0,50$, and 100 $\mathrm{mg}$ ) in PBS, pH 7.4 for $2 \mathrm{~h}$ at $37^{\circ} \mathrm{C}$ and overnight at $4^{\circ} \mathrm{C}$. The samples containing $10 \%$ glycerol and $0.002 \%$ bromophenol blue were applied and electrophoresis was carried out at $60 \mathrm{~V}$ for $6-8 \mathrm{~h}$ on $8 \%$ polyacrylamide gel. Staining of the gel was achieved with $0.1 \%$ Coomassie Brilliant Blue R 250 (in 25\% isopropanol and $10 \%$ glacial acetic acid). Destaining was carried out in a mixture of $10 \%$ acetic acid and $30 \%$ methanol.

\section{Results}

The UV absorption spectra of nitrated poly L-tyrosine showed peak shift of $4 \mathrm{~nm}$ towards shorter wavelength and $25 \%$ hypochromicity at $280 \mathrm{~nm}$ (Fig. 1). Another broad peak was observed at a wavelength of $420 \mathrm{~nm}$, which is characteristic of 3-nitrotyrosine. The modifications incurred on poly L-tyrosine were also analyzed by UV-difference spectroscopy (Fig. 1 inset) reiterating the results of UV spectra. The concentration of 3-nitrotyrosine in the nitrated homopolymer was calculated from the absorbance spectrum of a series of known concentrations of standard 3-nitrotyrosine at basic $\mathrm{pH}$ used as reference to determine the concentration of 3-nitrotyrosine in nitrated protein samples as well as by competitive ELISA. By these methods of quantitation, the concentration of 3-nitrotyrosine was found to be $0.39-\mathrm{mg} / 0.5 \mathrm{mg}$ protein and $0.35-\mathrm{mg} / 0.5 \mathrm{mg}$ protein, respectively. The average concentration of nitrated tyrosine determined was $0.37 \pm 0.028 \mathrm{mg} / 0.5 \mathrm{mg}$ protein solution of poly L-tyrosine. This data indicated at $74 \%$ nitration of the native polymer.

The modification induced by NO on poly L-tyrosine was confirmed by the use of radical quenchers, i.e., ascorbate, carboxy-PTIO and uric acid. Decrease in percent nitration to the extent of $91 \%, 84 \%$ and $73 \%$ was seen in the case of carboxy-PTIO, uric acid and ascorbic acid, respectively.

Alkaline agarose gel electrophoresis of native and nitrated poly L-tyrosine was performed on $0.6 \%$ agarose gel. The 


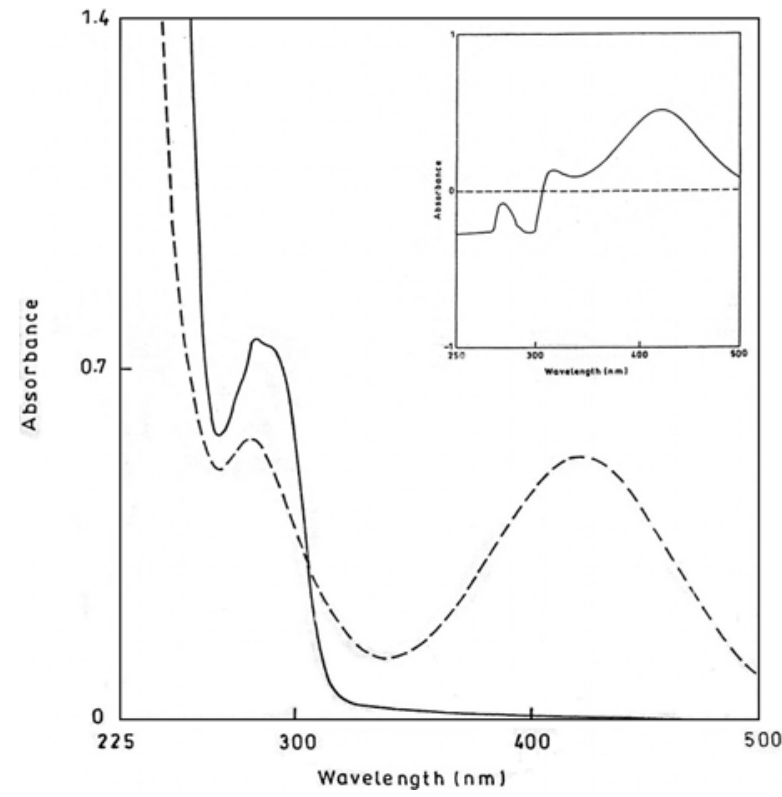

Fig. 1. UV absorption spectra of native (-) and nitrated poly Ltyrosine (---). Buffer used was phosphate buffer saline (PBS; 10 $\mathrm{mM}$ sodium phosphate, $150 \mathrm{mM} \mathrm{NaCl}, \mathrm{pH}$ 9). The concentration of native PLT is $0.5 \mathrm{mg} / \mathrm{ml}$ and the concentration of nitrated tyrosine was $0.37 \pm 0.028 \mathrm{mg} / 0.5 \mathrm{mg}$ protein solution of poly Ltyrosine. Inset: UV difference spectra of nitrated poly L-tyrosine. Native poly L-tyrosine served as control.

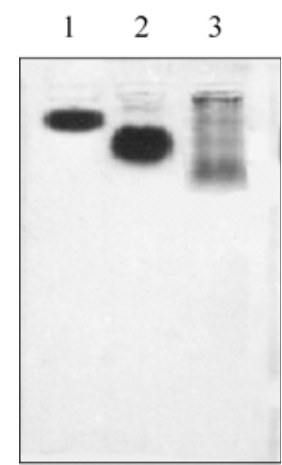

Fig. 2. Alkaline gel electrophoresis pattern of BSA (lane 1), native poly L- tyrosine (lane 2) and nitrated poly L- tyrosine (lane 3). Electrophoresis was carried out on $0.6 \%$ agarose for 4 $\mathrm{h}$ at $40 \mathrm{~mA}$. The gel was stained with Coomassie blue.

native sample migrated as a single band whereas the nitrated sample showed decrease in intensity with a broad band indicating formation of high and low molecular weight species (Fig. 2). The migration of BSA was hindered as the electrophoresis was performed in alkaline medium.

NO-poly L-tyrosine was found to be highly immunogenic inducing high titre (ELISA titre $>1: 12,800$ ) antibodies in rabbits (data not shown). The IgG purified from immune serum showed higher binding with immunogen than with the native form (Fig. 3a). Preimmune IgG showed negligible binding under identical conditions. In competition ELISA
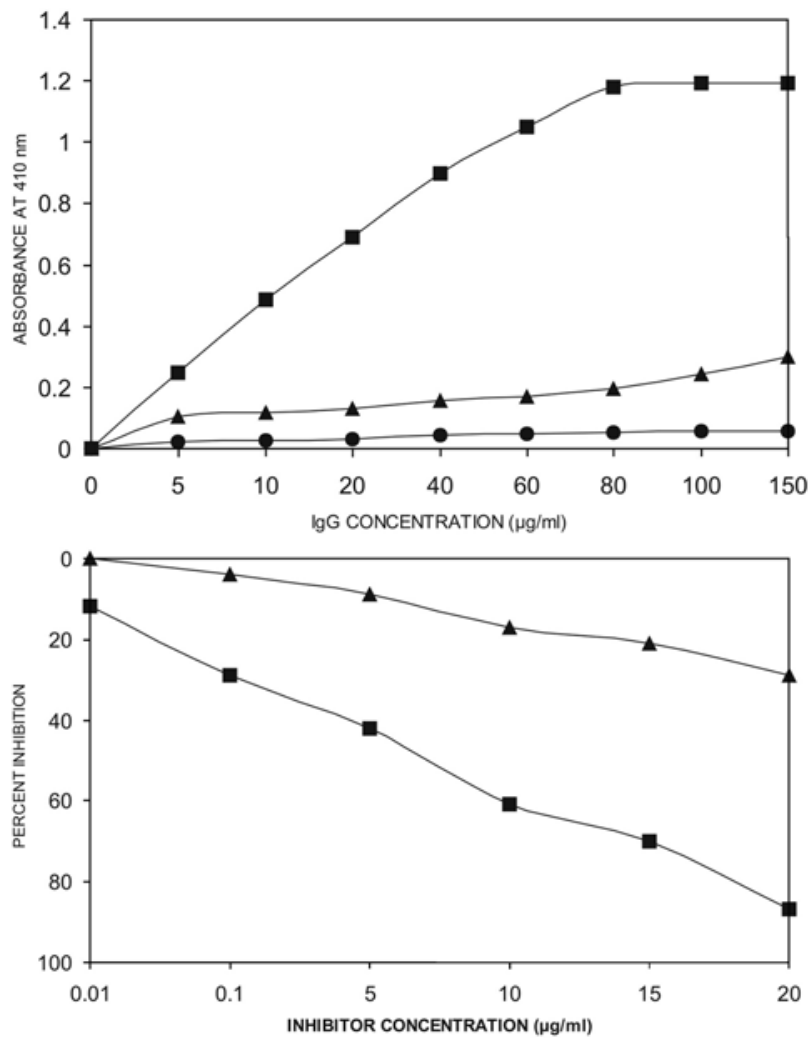

Fig. 3. (a) Direct binding ELISA of affinity purified preimmune IgG ( $\boldsymbol{O})$, anti-native $(\boldsymbol{\Delta})$ and anti-nitrated poly L-tyrosine $(\boldsymbol{\square})$ IgG. (b) Inhibition ELISA using anti-NO-poly L-tyrosine IgG The inhibitors were native ( $\boldsymbol{\Delta}$ ) and nitrated poly L-tyrosine ( $\boldsymbol{\square}$ ). The microtitre plates were coated with nitrated poly L-tyrosine $(2.5 \mu \mathrm{g} / \mathrm{ml})$.

(Fig. 3b) anti-NO-poly L-tyrosine IgG showed preference for immunogen. A maximum of $83 \%$ inhibition in antibody binding was observed using immunogen as competitor. Fifty percent inhibition was seen at immunogen concentration of 12 $\mu \mathrm{g} / \mathrm{ml}$. An array of polymers and their modified forms when exposed to reactive nitrogen species, were used as inhibitors to study the binding diversity of anti-NO-poly L-tyrosine antibodies (Table 1). The maximum inhibitions achieved were 74,72 and $79 \%$ with the nitrated forms of BSA, chromatin and $\mathrm{ONOO}^{-}$poly L-tyrosine, respectively. Inhibition with native forms of BSA, PLT, DNA, and chromatin, was 25\%, $29 \%, 17 \%$, and $35 \%$, respectively. Moderate inhibition was observed in the case of nitrated DNA $(52 \%)$.

HPLC of standard solution of 3-nitrotyrosine $(0.01 \mu \mathrm{M})$ dissolved in the eluant buffer $(500 \mathrm{mM}$ potassium phosphate, $\mathrm{pH}$ 3.0) was performed. A well defined peak of 3-nitrotyrosine at retention time of $\sim 7.2$ minute was observed (Fig. 4a). 3Nitrotyrosine was detected in the sera of immunized animals. The concentration of 3-nitrotyrosine in poly L-tyrosine immune sera was negligible $(0.018 \mu \mathrm{M})$ as compared to 0.90 $\mu \mathrm{M}$ in nitrated poly L-tyrosine immune sera (Fig. 4b,c).

To probe the possible role of nitrated poly L-tyrosine in the etiopathogenesis of SLE, sera showing high titre anti-DNA 
Table 1. Antigenic Binding Characteristics of Anti-Nitrated Poly L-Tyrosine IgG

\begin{tabular}{lc}
\hline \multirow{2}{*}{ Inhibitor } & Maximum \% inhibition at $20 \mu \mathrm{g} / \mathrm{ml}$ \\
\cline { 2 - 2 } & Anti-NO-poly L-tyrosine IgG \\
\hline Native BSA & 25 \\
Nitrated BSA & 74 \\
Native poly L-tyrosine & 29 \\
ONOO- poly L-tyrosine & 79 \\
Native DNA & 17 \\
Nitrated DNA & 52 \\
Native chromatin & 35 \\
Nitrated chromatin & 72 \\
\hline
\end{tabular}

autoantibodies $(1: 6400)$ were selected for binding to native and nitrated poly L-tyrosine. The sera showed substantially higher binding with the nitrated forms relative to native form of DNA and poly L-tyrosine. The same sera were subjected to competitive-inhibition assay using native DNA, native and nitrated poly L-tyrosine as competitors. The microtitre plates were coated with calf thymus DNA. The average percent inhibition $( \pm \mathrm{SD})$ of 24 SLE sera binding to native DNA showed significantly higher inhibition with NO-PLT (64 \pm 9$)$ than both native DNA $(49 \pm 8)$ and PLT $(35 \pm 11)$. There was a statistically significant difference on comparing the inhibition values of native DNA, PLT and nitrated poly L-tyrosine ( $p$ value of $<0.001$ ) (Table 2 ).

Gel retardation assay was carried out in polyacrylamide gel to visualize the formation of immune complexes. As clearly evident from the data (Fig. 5a), with increasing concentrations of NO-PLT $(0,50$, and $100 \mathrm{mg})$ there was a corresponding increase in the formation of high molecular weight immune complexes with immune IgG, which resulted in decrease in the intensity of unbound IgG. Decrease in intensity of IgG band and increase in immune complex formation was also seen between NO-PLT and SLE IgG (Fig. 5b). The concentration of IgG was kept constant (20 mg).

\section{Discussion}

Protein nitration has been suggested to be a final product due to interaction of highly reactive nitrogen oxide intermediates (e.g. $\mathrm{ONOO}^{-}$) formed in reactions between $\mathrm{NO}$ and oxygen derived species such as superoxide (Gunther et al., 2002). The most frequently studied marker of oxidative damage to proteins is protein carbonyl groups, oxidation/nitration of tryptophan, tyrosine and cysteine residue and protein fragmentation. 3-Nitrotyrosine is thought to be a relatively specific marker of oxidative damage mediated by $\mathrm{ONOO}^{-}$. The biological significance of tyrosine nitration is a subject of great interest, because ample evidence supports the formation of 3-nitrotyrosine in vivo in diverse pathological conditions.

In the present study, an aqueous solution of commercially available poly L-tyrosine was exposed to nitric oxide generated

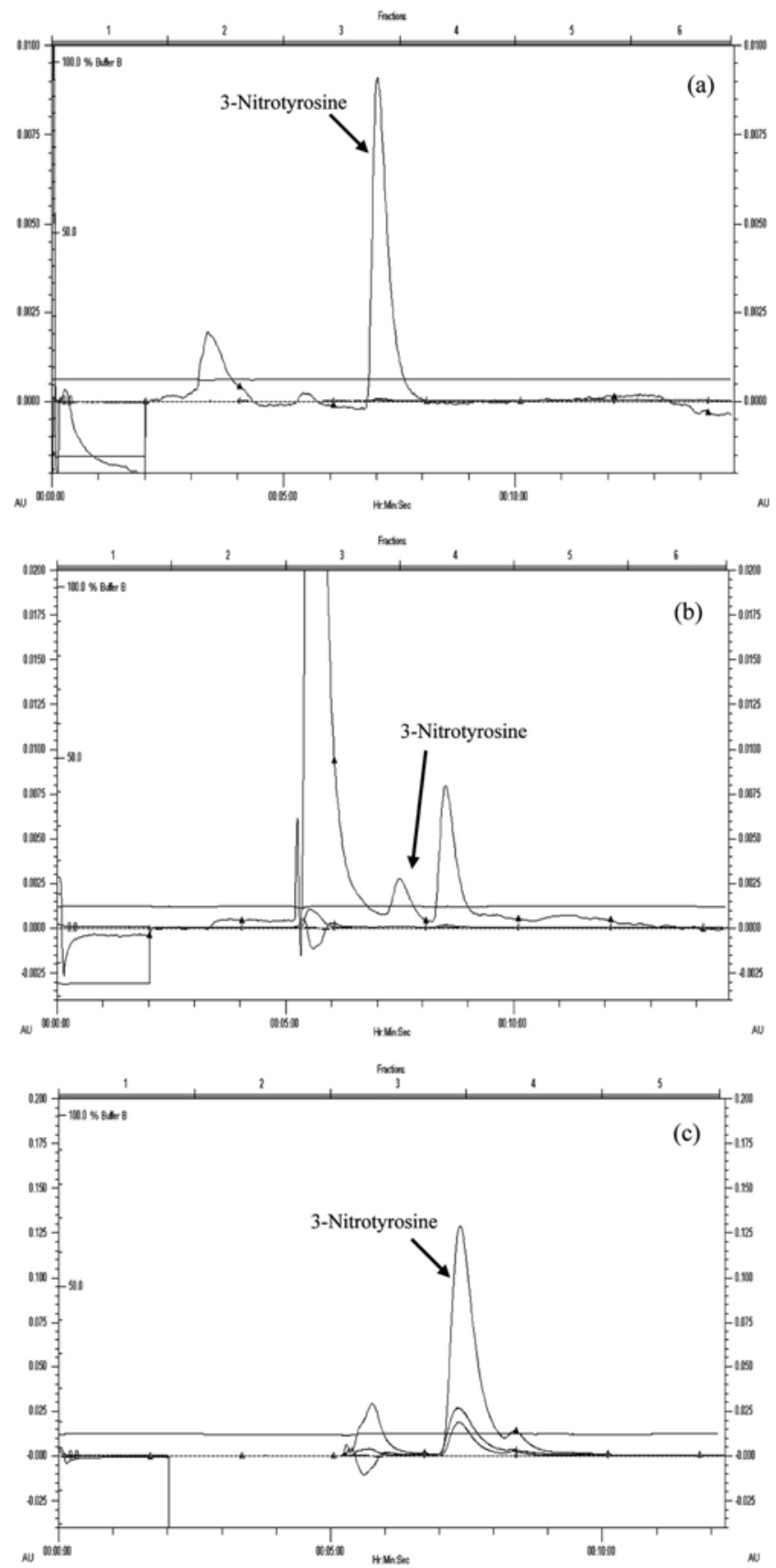

Fig. 4. (a) HPLC chromatograms of standard 3-nitrotyrosine at a concentration of $0.01 \mu \mathrm{M}$. Separation of 3-nitrotyrosine from (b) native and (c) nitrated poly L-tyrosine immune serum. Both the samples showed the presence of 3-nitrotyrosine at identical time retention as standard 3-nitrotyrosine.

by sodium nitrite in acidic medium. The production of nitric oxide radical was confirmed by the use of quenchers i.e., ascorbate, carboxy-PTIO, uric acid. Nearly complete inhibition in the production of $\mathrm{NO}$ was observed in the presence of carboxy-PTIO, and above $70 \%$ in the case of ascorbate and uric acid. The UV absorption spectra of nitrated poly Ltyrosine showed peak shift of $4 \mathrm{~nm}$ towards shorter wavelength 
Table 2. Inhibition of SLE Autoantibodies Binding to Native DNA by Native and Nitrated Poly L-Tyrosine

\begin{tabular}{|c|c|c|c|c|c|c|c|}
\hline \multicolumn{8}{|c|}{ Maximum percent inhibition at $20 \mu \mathrm{g} / \mathrm{ml}$} \\
\hline SLE serum & Native DNA & Native PLT & Nitrated PLT & SLE serum & Native DNA & Native PLT & Nitrated PLT \\
\hline 1 & 43 & 36 & 54 & 13 & 39 & 30 & 60 \\
\hline 2 & 44 & 32 & 49 & 14 & 56 & 30 & 57 \\
\hline 3 & 48 & 24 & 78 & 15 & 59 & 52 & 77 \\
\hline 4 & 40 & 35 & 52 & 16 & 57 & 36 & 78 \\
\hline 5 & 50 & 44 & 49 & 17 & 54 & 36 & 78 \\
\hline 6 & 53 & 22 & 58 & 18 & 44 & 56 & 71 \\
\hline 7 & 59 & 34 & 67 & 19 & 55 & 49 & 65 \\
\hline 8 & 39 & 30 & 50 & 20 & 41 & 31 & 72 \\
\hline 9 & 55 & 52 & 69 & 21 & 44 & 29 & 67 \\
\hline 10 & 65 & 54 & 71 & 22 & 43 & 20 & 62 \\
\hline 11 & 59 & 45 & 67 & 23 & 39 & 24 & 64 \\
\hline 12 & 40 & 31 & 55 & 24 & 49 & 19 & 59 \\
\hline
\end{tabular}

Poly L-tyrosine and native DNA: $\mathrm{t}=4.88, p<0.001$; Nitrated poly L-tyrosine and native DNA: $\mathrm{t}=6.05, p<0.001$; Nitrated and native poly L-tyrosine: $\mathrm{t}=9.79, p<0.001$

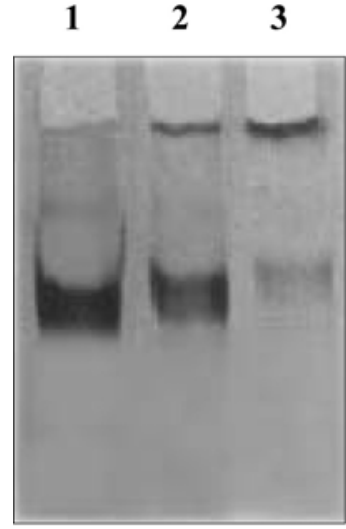

(A)

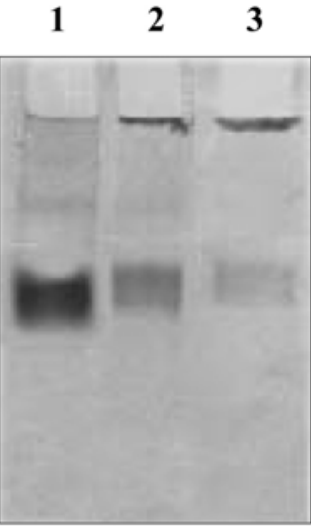

(B)
Fig. 5. Band shift assay of (a) anti-nitrated poly L-tyrosine $\operatorname{IgG}$ and (b) SLE IgG binding to nitrated poly L-tyrosine. Lane 1 contained $20 \mathrm{mg}$ antibody, while lanes 2 and 3 contained in addition $50 \mathrm{mg}$ and $100 \mathrm{mg}$ nitrated poly L-tyrosine. The mixture was incubated for $2 \mathrm{~h}$ at $37^{\circ} \mathrm{C}$ and subsequently overnight at $4^{\circ} \mathrm{C}$. Electrophoresis was carried out on $8 \%$ polyacrylamide gel for $4 \mathrm{~h}$ at $80 \mathrm{~V}$.

and $25 \%$ hypochromicity at $280 \mathrm{~nm}$. Another broad peak was observed at a wavelength of $420 \mathrm{~nm}$, which is characteristic of 3-nitrotyrosine. The observed change could be attributed to structural alterations as well as damage of chromophoric groups. Nitration of tyrosine residues in purified proteins is relatively easy to detect by visible spectroscopy owing to the characteristic yellow colour, which was observed in this case. The results are indicative of an appreciable portion of NO induced damage of the aromatic ring of tyrosine, as well as nitration of tyrosine forming 3-nitrotyrosine. Formation of high and low molecular weight species indicating aggregation and peptide bond cleavage of nitrated poly L-tyrosine was seen in the alkaline agarose gel electrophoresis.

Both free and protein bound 3-nitrotyrosine dramatically increased in pathologic conditions associated with the production of reactive oxygen and nitrogen species. There is mounting evidence that nitration of tyrosine residues in proteins can profoundly alter protein function, suggesting that protein nitration may be fundamentally related to, and be predictive of oxidative cell injury. The subsequent release of altered proteins during various cell functions may enable it to act as an antigen inducing antibodies crossreacting with selfproteins. At the very least, the presence of 3-nitrotyrosine in biological samples indicate that reactive nitric oxide derived species were produced in vivo, although the exact nature of these species remains to be determined (Crow, 1999). The immunoreactivity of 3-nitrotyrosine has been reported in several human pathological conditions as mentioned earlier. In addition, numerous other disease states using non-human models have been shown to involve formation of 3-nitrotyrosine (Crow, 1999).

Nitrated poly L-tyrosine was found to be immunogenic in rabbits as revealed by the result of direct binding and inhibition ELISA. Band shift assay clearly demonstrated the specificity of the purified immune IgG towards the immunogen. Antigenic specificity of purified $\mathrm{IgG}$ was confirmed by inhibition ELISA. A maximum of $83 \%$ inhibition in the binding of anti-nitrated poly L-tyrosine antibody with immunogen as inhibitor was observed at $20 \mu \mathrm{g} / \mathrm{ml}$ and, 50\% inhibition was achieved at $12 \mu \mathrm{g} / \mathrm{ml}$. These results suggest that the nitration of tyrosine results in the generation of neoepitopes, making it a potential immunogen. The antibody developed can be used as a probe for detecting the presence of 3-NT, demonstrating NO-mediated pathology and testing the effectiveness of therapeutic aids in preventing damage by reactive nitrogen species.

The separation and quantitation of 3-nitrotyrosine was also 
carried out by HPLC. The serum from the animals immunized by native poly L-tyrosine showed negligible 3-nitrotyrosine level when compared to 3-nitrotyrosine present in the nitrated poly L-tyrosine immune serum. This could be correlated to a feature in SLE wherein elevated level of nitrated free or protein bound tyrosine (neoantigen) play a major role in the production of SLE autoantibodies.

Most lesions in murine and human systemic lupus erythematosus (SLE) are considered to be associated with the presence of anti-double-stranded DNA (dsDNA) antibodies that are spontaneously produced in large amounts (Jacob et al., 1986). SLE anti-DNA autoantibodies exhibit polyspecificity with respect to antigen binding (Waris and Alam, 2004). It has been reported that self-proteins bearing 3-nitrotyrosine are generated in inflamed tissues where activated inflammatory cells may release peroxynitrite, a naturally occurring nitrating agent (Ohmori et al., 2005). The antigenicity of nitrated-PLT was evaluated and the binding characteristics of induced antibodies have been determined. It has been found that induced antibodies recognized DNA, BSA and chromatin besides poly L-tyrosine exposed to reactive nitrogen free radicals. The antibodies showed appreciably less binding with the native forms of these polymers. It has been reported that a part of anti-DNA antibodies produced in MRL/lpr mice showed crossreactivity with 3-nitrotyrosine and 3-NT-bearing self proteins (Ohmori et al., 2005). This intrinsic crossreactivity is the basis for the ability of 3-NT to induce DNA-cross reactive anti-3-NT antibodies. Thus, anti-3-NT antibody responses to nitrated poly L-tyrosine might be a potential trigger leading to anti-DNA antibody formation under some pathologic conditions. This immune response also may contribute to the clearance of NT-bearing self-proteins.

Autoantibodies targeted against intracellular proteins and nucleic acids are the serological hallmark of the systemic rheumatic diseases, such as systemic lupus erythematosus (SLE), progressive systemic sclerosis (PSS), Sjogren's syndrome (SS), mixed connective tissue disease (MCTD) and polymyositis (PM). Each one of these diseases is identified by the unique autoantibodies. Several retrospective studies have indicated a correlation between serum nitrate/nitrite level and disease activity. It has also been found that serum 3-nitrotyrosine level is elevated among patients with SLE (Oates et al., 1999; Gilkeson et al., 1999). The level of 3-nitrotyrosine was found elevated in immunized rabbits. In the present study, the possible role of native and nitrated poly L-tyrosine in SLE was probed. Autoantibodies in twenty-four different SLE sera were screened by direct binding and competition ELISA. All sera showed stronger binding to nitrated poly L-tyrosine when compared to native poly L-tyrosine and nDNA. The band shift assay reiterated the results obtained by competition ELISA. No detectable antibody activity was found in the pooled normal human sera.

These studies demonstrated that nitration of tyrosine resulted in the formation of neoantigen(s) thus inducing explicit immune response. When compared with dsDNA and native poly L-tyrosine, nitrated-PLT level correlated better with SLE subjects. The data confirms the overproduction of NO and intermediates in human SLE and points out serum 3nitrotyrosine as a new diagnostic tool for studying the role of nitric oxide in SLE and other diseases where production of NO is prevalant.

Acknowledgments. The research work is supported by a grant (no. 52/4/2001-BMS) to R.A. from Indian Council of Medical Research, India. We are also thankful to Asim A. Siddiqui of All India Institute of Medical Sciences, New Delhi for helping us out with some experiments required for this study.

\section{References}

Ali, R. and Alam, K. (2002) Evaluation of antibodies against oxygen free radical-modified DNA by ELISA. Methods Mol. Biol. 186, 171-181.

Arnett, F. C., Edworthy, S. M., Bloch, D. A., McShane, D. J., Fries, J. F., Cooper, N. S., Healey, L. A., Kaplan, S. R., Liang, M. H. and Luthra, H. S. (1998) The American Rheumatism Association 1987 revised criteria for the classification of rheumatoid arthritis. Arth. Rheum. 31, 315-324.

Belmont, H. M., Levartovsky, D., Goel, A., Amin, A., Giorno, R., Rediske, J., Skovron, M. L. and Abramson, S. B. (1997) Increased nitric oxide production accompanied by the upregulation of inducible nitric oxide synthase in vascular endothelium from patients with systemic lupus erythematosus. Arth. Rheum. 40, 1810-1816.

Brito, C., Naviliat, M., Tiscornia, A. C., Vuillier, F., Gualco, G., Dighiero, G., Radi, R. and Cayota, A. M. (1999) Peroxynitrite inhibits $\mathrm{T}$ lymphocyte activation and proliferation by promoting impairment of tyrosine phosphorylation and peroxynitrite-driven apoptotic death. J. Immunol. 162, 3356-3366.

Brown, G. C., McBride, A. G., Fox, E. J., McNaught, K. S. and Borutaite, V. (1997) Nitric oxide and oxygen metabolism. Biochem. Soc. Trans. 25, 901-904.

Cassina, A. and Radi, R. (1996) Differential inhibitory action of nitric oxide and peroxynitrite on mitochondrial electron transport. Arch. Biochem. Biophys. 328, 309-316.

Crow, J. P. (1999) Measurement and significance of free and protein-bound 3-nitrotyrosine, 3-chlorotyrosine, and free 3nitro-4-hydroxyphenylacetic acid in biologic samples: A highperformance liquid chromatography method using electrochemical detection. Methods Enzymol. 301, 151-160.

Davies, K. J. (1987) Protein damage and degradation by oxygen radicals. I. general aspects. J. Biol. Chem. 262, 9895-9901.

Davies, K. J. and Delsignore, M. E. (1987) Protein damage and degradation by oxygen radicals. III. Modification of secondary and tertiary structure. J. Biol. Chem. 262, 9908-9913.

Davies, K. J., Delsignore, M. E. and Lin, S. W. (1987) Protein damage and degradation by oxygen radicals. II. Modification of amino acids. J. Biol. Chem. 262, 9902-9907.

Dixit, K. and Ali, R. (2004) Role of nitric oxide modified DNA in the etiopathogenesis of systemic lupus erythematosus. Lupus. 13, 95-100. 
Dixit, K., Ahsan, H. and Ali, A. (2003) Polydeoxyribonucleotide C photoconjugated with lysine or arginine present unique epitopes for human anti-DNA autoantibodies. Hum. Immunol. 64, 880-886.

Gilkeson, G., Cannon, C., Oates, J., Reilly, C., Goldman, D. and Petri, M. (1999) Correlation of serum measures of nitric oxide production with lupus disease activity. J. Rheumatol. 26, 318324.

Gunther, M. R., Sturgeon, B. E. and Mason, R. P. (2002) Nitric oxide trapping of the tyrosyl radical-chemistry and biochemistry. Toxicology 177, 1-9.

Hal, S. R., Kurien, B. T., Ganick, S., McClain, M. T., Pye, Q., James, J. A., Schneider, R. I., Broyles, R. H., Bachmann, M. and Hensley, K. (2005) Modification of lupus-associated 60$\mathrm{kDa}$ Ro protein with the lipid oxidation product 4-hydroxy-2nonenal increases antigenicity and facilitates epitope spreading. Free Radic. Biol. Med. 38, 719-728.

Hasan, R. and Ali, R. (1990) Antibody recognition of common epitopes on Z-DNA and native DNA brominated under high salt. Biochem. Int. 20, 1077-1088.

Hasan, R., Ali, A. and Ali, R. (1991) Antibodies against DNApsoralen crosslink recognize unique conformation. Biochim. Biophys. Acta. 1073, 509-513.

Jacob, L., Lety, M. A., Bach, J. F. and Louvard, D. (1986) Human systemic lupus erythematosus sera contain antibodies against cell-surface protein(s) that share(s) epitope(s) with DNA. Proc. Natl. Acad. Sci. USA 83, 6970-6974.

Kaur, H. and Halliwell, B. (1994) Evidence for nitric oxidemediated oxidative damage in chronic inflammation. Nitrotyrosine in serum and synovial fluid from rheumatoid patients. FEBS Lett. 350, 9-12.

Khan, J., Brennand, D. M., Bradley, N., Gao, B., Bruckdorfer, R., and Jacobs, M. (1998) 3-Nitrotyrosine in the proteins of human plasma determined by an ELISA method. Biochem. J. 332, 807-808.

Lepoivre, M., Fieschi, F., Coves, J., Thelander, L. and Fontecave, M. (1991) Inactivation of ribonucleotide reductase by nitric oxide. Biochem. Biophys. Res. Commun. 179, 442-448.

Lopez-Nevot, M. A., Ramal, L., Jimenez-Alonso, J. and Martin, J. (2003) The inducible nitric oxide synthase promoter polymorphism does not confer susceptibility to systemic lupus erythematosus. Rheumatology 42, 113-116.
Mansoor, F., Ali, A. and Ali, R. (2005) Binding of circulating SLE autoantibodies to oxygen free radical damaged chromatin. Autoimmunity 38, 431-438.

Nguyen, T., Brunson, D., Crespi, C. L., Penman, B. W., Wishnok, J. S. and Tannenbaum, S. R. (1992) DNA damage and mutation in human cells exposed to nitric oxide in vitro. Proc. Natl. Acad. Sci. USA 89, 3030-3034.

Oates, J. C., Christensen, E. F., Reilly, C. M., Self, S. E. and Gilkeson, G. S. (1999) Prospective measure of serum 3nitrotyrosine levels in systemic lupus erythematosus: correlation with disease activity. Proc. Assoc. Am. Physicians. 111, 611621.

Ohmori, H., Oka, M., Nishikawa, Y., Shigemitsu, H., Takeuchi, M., Magari, M. and Kanayama, N. (2005) Immunogenicity of autologous IgG bearing the inflammation-associated marker 3nitrotyrosine. Immunol. Lett. 96, 47-54.

Ohshima, H., Friesen, M., Brouet, I. and Bartsch, H. (1990) Nitrotyrosine as new marker for endogenous nitrosation and nitration of proteins. Food Chem. Toxicol. 28, 647-652.

Reynolds, M. R., Berry, R. W. and Binder, L. I. (2005) SiteSpecific Nitration and oxidative dityrosine bridging of the tau protein by peroxynitrite: implications for Alzheimer's disease. Biochemistry 44, 1690-1700.

Robert, P. and Kimberly, M. D. (2001) Research advances in systemic lupus erythematosus. J. Am. Med. Assn. 285, 650-651.

Tsikas, D. and Caidahl, K. (2005) Recent methodological advances in the mass spectrometric analysis of free and protein-associated 3-nitrotyrosine in human plasma. $J$. Chromatogr. B. Analyt. Technol. Biomed. Life Sci. 814, 1-9.

Wanchu, A., Khullar, M., Deodhar, S. D., Bambery, P. and Sud, A. (1998) Nitric oxide synthesis is increased in patients with systemic lupus erythematosus. Rheumatol. Int. 18, 41-43.

Waris, G. and Alam, K. (2004) Immunogenicity of superoxide radical modified-DNA: Studies on induced antibodies and SLE anti-DNA autoantibodies. Life Sci. 75, 2633-2642.

Xiao, G. G., Nel, A. E. and Loo, J. A. (2005) Nitrotyrosinemodified proteins and oxidative stress induced by diesel exhaust particles. Electrophoresis 26, 280-292.

Yoshie, Y. and Ohshima, H. (1997) Synergistic induction of DNA strand breakage caused by nitric oxide together with catecholamine: implications for neurodegenerative disease. Chem. Res. Toxicol. 10, 1015-1022. 